Jacqueline is a 49 -year-old school nurse team leader based in East Yorkshire. Her work covers 25 primary schools and three senior schools in Eastern Hull and is primarily a public health role, raising awareness of the importance of healthy living and making informed decisions.

Ann is a part-time health visitor based in Greater Manchester with 15 years' experience. Ann deals mainly with vulnerable families, helping them make informed choices about their child's health and instilling good habits early on.

What oral health advice do you give your patients?

Jacqueline We stress the importance of regular dental check-ups and advise not to ignore toothache. We get consent from the parents to give us their children's health information and if the child is not registered with a dentist we try to address that by generating a letter that includes a list of registered dentists within Hull. We talk to children about how to brush their teeth, how often and for how long and how much toothpaste is required. We advise them not to rinse after brushing their teeth and to change their toothbrush regularly.

We also give dietary advice on issues such as the dangers of hidden sugars, taking sugars with meals and reducing snacking, and promote water and milk over carbonated drinks.

Ann It varies considerably. Some [parents] have read every book they can get their hands on but are confused as all the books give slightly different advice, while others don't even access antenatal care.

One of the main problems we have is that parents put juice in feeding bottles, which is one

\title{
DO HEALTH PROFESSIONALS SING FROM THE SAME HYMN SHEET? PART 1
}

What do non-dental health professionals advise patients when it comes to the oral cavity?

In a series of interviews for Vital magazine (soon to be re-launched as BDJ Team), we spoke to a health visitor and a school nurse. An interview with a dietitian is next on the agenda. Excerpts from the first two interviews are reproduced here. ${ }^{1,2}$

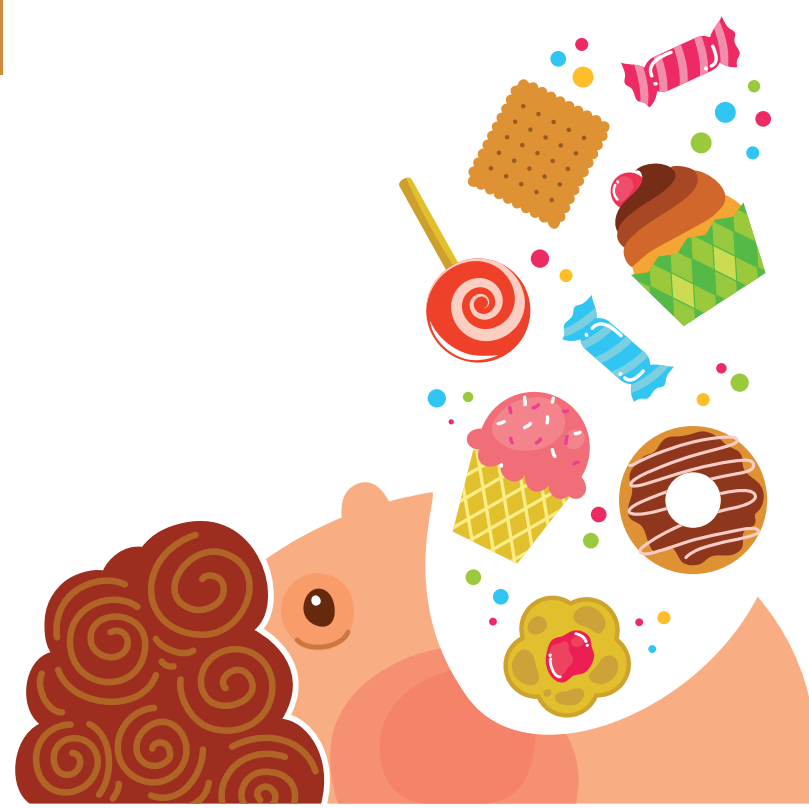

'It can be very difficult to try to get through to the parents that if they carry on with this practice then their child is probably going to have dental decay before they go to school...'

of the worst things you can do as far as oral health is concerned. It can be very difficult to try to get through to the parents that if they carry on with this practice then their child is probably going to have dental decay before they go to school. Many are more vigilant now when it comes to children's teeth but there's still a lot of work to do and we frequently have to remind them about avoiding the number of times they give their children sugary substances. It's probably slightly different where we are, as we have soft water and no fluoride supplements, but we encourage the use of family toothpaste for children rather than children's toothpaste because there's not enough fluoride in it. We've always said it doesn't matter that the child can't rinse its teeth and now of course we know it's okay to leave the toothpaste on because why would you use fluoride and then rinse it off? We advise that toothpaste is left on the teeth.

Has the oral health advice you give changed over the years?

Jacqueline In some ways it has with research. A lot of children have electric toothbrushes now, but you still have to remind them to brush their teeth for two minutes and not up and down but in a circular motion. There has been increasing focus on looking after the gums as well as the teeth, so we emphasise the need to care for the gum margins too. Most importantly advice on rinsing has changed. In the past the old method was to rinse at the end of brushing, which removes the effects of the fluoride. We're not in a fluoridated water area, so it makes it even more important not to rinse.

Ann It's not changed that much since 1999 when I first started working as a health visitor. In general it's the weaning advice that changes. It's now six months before they recommend weaning but originally it was three months and then it was four months. The new recommended weaning age is something that is often hard for new parents to accept because some grandmas are still saying they need weaning before then. They claim to have weaned their children at two months, for example, without it doing any harm, so the main thing is not to antagonise and try and get grandma on your side - you get a lot further! You have to give the rationale behind why you're saying what you're saying and then they have to make their own informed choice.

\section{Have children's teeth changed} over the years you have been a school nurse?

Jacqueline I think it has remained pretty much the same, with a certain 
portion of the population still having a large amount of dental decay. Shockingly, we're still seeing children have a full dental clearance and in these cases the dentists do make us aware of these families.

There was a period when dentists were very difficult to access, but now there is no reason why a child shouldn't have a dentist. Dental health is often taken less seriously, with parents passing on phobias and dental scare stories to their children. We've got better facilities in schools now for children who do either have phobias or special needs, so dentists can access these children when they normally wouldn't even get through the practice door.

Do you assess dental neglect in children?

Ann It's part of the general assessment and has been stressed particularly in the last couple of years. We don't actually open the mouth and have a look but in the general assessment you can gauge a child's oral health. If you can see there's a build-up of plaque or the gums are inflamed then you would be concerned. Often the parents have the same symptoms and it's quite a hard situation to handle if the mum has poor dental care; you have to be quite tactful.

Often parents think it doesn't matter if [the decayed teeth are] just baby teeth, so you have to explain the importance of baby teeth in relation to general health and in relation to the second set of teeth that come through, as well as stress how decayed teeth may be causing pain at the time. We're lucky to have a community dentist at the local health centre who will see any children that we're worried about.

Who do you think is responsible for child dental health?

Jacqueline I think foremost the parents but everyone nationally has a responsibility to try and improve children's dental health. If everyone took part of the responsibility it would reduce costs to the NHS for dental treatment and reduce the number of children being put through unnecessary treatment.

What are your top tips to new parents for their child's dental health?

Ann Stick to breast or formula milk for the first six months; prepare your own food then you've got control over the amount of sugars and salt in the meal; and avoid giving sugary snacks: this is a fast track to tooth decay. 1. Pacey L. 'One of the main problems is that parents put juice in
feeding bottles.' Vital summer 2013; 46-47.

2. Pacey L. 'We're still seeing children have a full clearance.' Vital winter 2013; 22-24.

\section{BY LAURA PACEY WITH KATE QUINLAN}

If you or members of your dental team would like to sign up for BDJ Team, which will be published online and offer ten free hours of CPD this year, just email k.quinlan@nature.com with your details.

\section{TWO HEALTH GIANTS UNITE TO PUBLISH MANUAL}

The International College of Dentists' (ICD) European Section, through the Philip Dear Fund, has sponsored the 5th edition of the World Health Organisation (WHO) manual Oral health surveys, basic methods. The liaison with the WHO is an historic milestone allowing ICD Fellows anywhere in the world to access essential information when planning and monitoring the hundreds of humanitarian projects carried out by sections of the College.

The manual outlines the principles of clinical oral health surveys as recommended by the WHO and includes guidance for conducting surveys, diagnostic criteria, the reliability of data and the

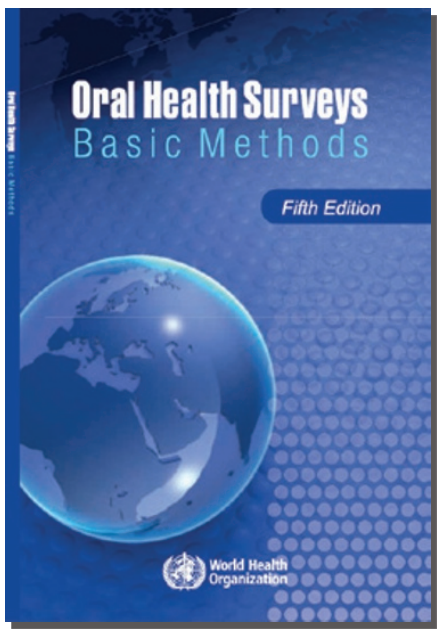
selection of participants.

The public health problems associated with oral disease are a serious burden on countries around the globe, and the WHO has a long tradition of epidemiological survey methodology and surveillance in oral health, while the ICD has been focused on increasing educational and humanitarian aid projects worldwide. This collaboration marks a true symbiosis between two of the world's most respected health organisations.

www.icd.org/content/publications/WHO-Oral-Health-Surveys-BasicMethods-5th-Edition-2013.pdf

\section{HONOURS, AWARDS, APPOINTMENTS}

Practice of the year commendation

Cedar Dental Care was awarded a commendation by the BDA in their Good

Practice Scheme Practice of the Year Award. Cedar Dental Care was the only practice in the UK to be awarded a commendation.

\section{Visiting Professor}

Dr Paul Tipton has been awarded the honorary title Visiting Professor following his appointment as programme leader for the City of London Dental School's new MClintDent modules in restorative and cosmetic dentistry. Professor Tipton is the founder of Tipton Training.

Elective prizes

Saul Konviser, a fifth year undergraduate student at King's College London Dental Institute who spent his elective placement in Cape Town, has won both the 2013 Dental Protection Student of the Year Award and the Dental Students Elective Prize, awarded by the Global Child Dental Fund (GCDFund) at the Dental Institute.

\section{IN THIS ISSUE}

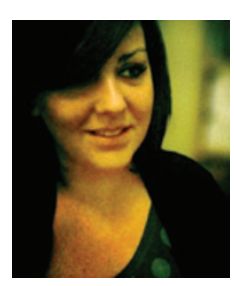

$B D J$ Production Editor Esther McKeown is the mastermind behind the crisp design of the pages of the $B D J$, and most recently has redesigned the 'Upfront' section of the journal, incorporating News.

Esther joined what is affectionately known internally as 'Team $B D J$ ' in 2005, at the same time relocating from Shakespeare country to a chic apartment in Wapping, by the Thames.

Recent years have seen Esther follow her heart to Manchester and she currently has Team $B D J$ 's longest commute!

Did you know? Esther bakes and decorates professional-standard cakes for friends and family. In another life she was Assistant Editor of Rotary, the official magazine of Rotary International in Great Britain and Ireland. 